\title{
FATAL ENCEPHALOPATHY IN GLANDULAR FEVER
}

\author{
BY \\ J. D. BERGIN \\ From Wellington Hospital, New Zealand
}

In 1931, Epstein and Dameshek reported a case of meningo-encephalitis complicating glandular fever and in the same year Johansen described a similar case. From 1940 onwards there were a number of reports of individual cases, or small groups of cases, with one or other of the central nervous system complications now known to occur in this disease. Such reports came mainly from North America and Europe, but also from Great Britain and South Africa. No single author has had experience of any large number of cases although some have reviewed the literature at the date of their own reports and have provided a comprehensive picture of the varied forms in which the nervous system can be affected. An account of these varied neurological manifestations of the condition has been provided by Kissel, Arnould, and Léval (1952). Landes, Reich, and Perlow (1941) referred to a dozen cases in the literature; Bernstein and Wolff (1950) reviewed 34 published cases; Silversides and Richardson (1950) collected 59; Freedman, Odland, and Cleve (1953) found 54 cases and Leibowitz (1953) reviewed 71 in his monograph on glandular fever; Walsh, Poser, and Carter (1954) spoke of approximately 100 cases in the literature.

The overall incidence of central nervous system involvement, represented by the collected reports of particular cases, may afford a picture of the chances of the development of central nervous system lesions in one or other form in this condition. Halcrow, Owen, and Rodger (1943) reviewed 296 cases and found that five had meningeal symptoms sufficient to warrant lumbar puncture, and, taking these as indicative of nervous system involvement, the incidence in his series was between $1 \%$ and $2 \%$. Silversides and Richardson (1950) found a group of reports in which the cases reviewed totalled 4,393, among which there were 17 with central nervous system involvement, the incidence of neurological complications on this background being under $1 \%$. Rugg-Gunn (1954) found figures in other authors' reports which led him to state the incidence as varying from less than $1 \%$ up to $5 \%$. In his own series of 412 cases there were three with definite involve- ment of the nervous system, an incidence of less than $1 \%$. An estimate of between $1 \%$ and $2 \%$ for the likelihood of neurological complications is reasonable, and is one which would be in keeping with the experience of most physicians.

A striking variety of neurological disorders has been recorded in glandular fever. At first there may seem little logical connexion between the numerous manifestations, but when the clinical pictures are considered as a whole, it will be seen that they represent disturbances of various parts of the nervous system reflecting the generalized nature of the primary disorder in the body. The commonest variety of nervous system affection is serous meningitis. The earliest reported cases were of this variety: 10 of Bernstein and Wolff's (1950) 34 neurological cases, 28 of the 59 collected by Silversides and Richardson (1950), and 15 of the 71 analysed by Leibowitz (1953) were meningitic. The exudate is lymphocytic, and glandular fever is now a well-recognized member of the group to be considered when faced with a lymphocytic meningitis difficult of elucidation. Tidy (1946) has gone so far in the past as to challenge the existence of the entity which goes under the name of benign lymphocytic meningitis, his argument being that none of the published cases of this condition were proved not to have glandular fever, and that all of them had clinical features consistent with those seen in glandular fever with meningeal involvement.

Encephalitis has been reported less commonly than meningitis although there have been many cases with both meningitic and encephalitic features more properly termed meningo-encephalitic, and likewise there are some on record with encephalitic and spinal cord lesions appropriately designated encephalo-myelitic. Crowther (1951) described a case of encephalitis and found four others in the literature in the previous 20 years. Librach (1952) published a case of encephalitis and later (1954) another. Other individual reports of encephalitis have come from Landes et al. (1941), Zohman and Silverman (1942), Geliebter (1946), Slade (1946), Schneider and Michelson (1947), Dolgopol and 
Husson (1949), McNeel (1951), and Hubler, Bailey, Campbell, and Mathieson (1951). Nineteen of the 59 cases collected by Silversides and Richardson (1950), four of the 34 reported by Bernstein and Wolff (1950), and 15 of the 71 reviewed by Leibowitz (1953) were encephalitic. A report by Green (1955) has described the occurrence of hemiplegia in a young woman during the course of glandular fever, this manifestation being regarded as possibly based on a focal encephalitic lesion.

Cases in which the principal features have been those of cerebellar disorder are on record. This was so in the case reported by Hoyne (1950) where glandular fever was unmistakable, and vertigo and ataxia persisted for a long time. These authors refer to a case previously published by Landes et al. (1941) in which giddiness, unsteadiness, and acute ataxia were present although no attempt was made to localize the responsible lesion. In the case of Freedman et al. (1953) there was difficulty in coordinating movements of the limbs during the convalescent phase. Seltzer (1953) described a case with ataxia of cerebellar origin although the patient had polyneuritic features in addition. Walsh et al. (1954) described a child with glandular fever troubled with cerebellar symptoms after recovery from a more acute cerebral disorder. They reviewed records of 35 cases of glandular fever at the Columbia Presbyterian Medical Center and found three patients in whom the central nervous system appeared to be involved and one of whom had signs of cerebellar disorder.

Cranial nerve lesions, usually in association with more general involvement of the nervous system, are known. Anosmia was mentioned by Marchal, Bargeton, and Mahoudeau (1933); Halcrow et al. (1943) refer to one of their few cases with meningeal symptoms as having optic neuritis for a period of two months; Ashworth and Motto (1947) described a case with bilateral papilloedema, regarding it, in the presence of a normal pressure in the cerebrospinal fluid, as a manifestation of optic neuritis. Piel, Thelander, and Shaw (1950) have reported a case with encephalitis and bilateral papilloedema but "normal cerebrospinal fluid dynamics." Disturbances of ocular innervation have been described by Fledelius (1935) who reported paresis of the inferior rectus and by Vaughan, Regan, and Terplan (1946) whose case had an external rectus palsy. Unilateral facial palsy has been described by Gsell (1937) and facial diplegia was present as the only neurological feature in one of Silversides and Richardson's (1950) cases as also in that described by Creaturo (1950) where it was part of a more general polyneuritic picture. Kissel et al. (1952) found accounts of six cases of unilateral or bilateral facial palsy.
Isolated peripheral nerve involvement in the form of serratus magnus palsy occurring during the course of glandular fever has been described by Richardson (1942) and Saksena (1943). Kissel et al. (1952) refer to other reported cases indicative of partial brachial plexus lesions.

One of the commonest forms of nervous system involvement encountered has been acute polyneuritis, a complication which has been responsible for some of the fatalities in glandular fever. Cases showing the clinical feature of both glandular fever and acute polyneuritis have been reported by Hiller and Fox (1943), by Coogan, Martinson, and Mathews (1945), and by Graham, Schwartz, and Chapman (1949). Ricker, Blumberg, Peters, and Widerman (1947) examined the records of the U.S. Army Institute of Pathology and found 36 fatal cases of the Guillain-Barré syndrome and nine fatal cases of glandular fever. There were two in which both glandular fever and the Guillain-Barré syndrome coexisted. The same cases were reported and discussed more from the clinical point of view by Peters, Widerman, Blumberg, and Ricker (1947). Creaturo (1950) described a case with facial diplegia as part of the picture of acute polyneuritis. RuggGunn (1954) had one case of polyneuritis among the 412 naval men with glandular fever who had been surveyed by him. Garvin (1953) reported a further case, pointing out that of the 10 known at that date four had been fatal; Fiese, Cheu, and Radding (1953) reported polyneuritis in an older person with glandular fever and noted the total reported cases as 15 at that date.

A case report of special interest in relation to the one which follows in this paper is that of Raymond and Williams (1948), who reported the occurrence of what appeared to be acute schizophrenia during the course of glandular fever with complete resolution as the infection subsided.

\section{Case History}

A. B., a man aged 21 , possessed a family history and previous medical history which were healthy. Six weeks before the onset of his acute illness he had had an inguinal hernia repaired and when seen three weeks later for post-operative follow-up, he complained to the surgeon of a sore throat which was not severe at the time. A fortnight later he again complained of sore throat and this time of back-ache as well, but, on that day he had felt well enough to dine out in the evening. The following morning his throat was more painful and he was feverish. During the day his temperature rose, he began to have rigors, and in the afternoon began to retch and vomit. Late in the afternoon he was shivering and perspiring profusely, appeared confused, and seemed to have difficulty in swallowing and talking. Widespread localized jerking movements were noted. The throat 
was inflamed but there were no other abnormal signs. During the evening he was generally quieter but the twitching persisted; he did not enter into conversation but appeared to recognize people and smile at them. During the night he left his bed in a confused state and passed urine in a corner of the lounge. By the following morning the temperature was still raised to $103^{\circ} \mathrm{F}$. and the general condition unchanged, except that he had become more unresponsive, and although the eyes remained open they did not focus on surrounding objects. He broke silence only once to swear emphatically at a particular aspect of the examination. Jerking movements involving face and limb muscles still occurred but there were no other physical signs. Although there was ample evidence of infection in the form of fever and sore throat and some form of encephalitis was under consideration, the strange withdrawn attitude, the mutism and leering grin raised the question of an acute schizophrenic reaction. Later in the day definite neck stiffness appeared and the patient was transferred to the Wellington Hospital where lumbar puncture showed the fluid under normal pressure and containing only 3 cells ; the protein content was $42 \mathrm{mg}$. per c.mm. The total leucocyte count of the blood was 9,200 at which level a differential picture was not requested immediately. During the night he lost all responsiveness to stimuli and the following morning had the first of several generalized convulsions. Re-examination at this stage revealed a chain of enlarged lymph nodes in the posterior cervical region on either side, and examination of the stained film from the blood drawn on admission 12 hours earlier showed $58 \%$ abnormal mononuclear cells typical of glandular fever cells. The Paul-Bunnell serological test for heterophil antibodies was positive to a titre of 1 in 114,688 , reduced to 1 in 14,366 after absorption with guinea-pig kidney, and 1 in 448 after absorption with ox red cells.

Soon after the onset of convulsions the condition changed to one of decerebrate rigidity with bilateral extensor plantar responses, and at this stage much of the localized muscle twitching ceased although localized tonic and clonic movements involving the face and jaw, and sometimes also the arms and shoulders, were still seen. Respiration became irregular, rigidity persisted, and hyperpyrexia developed. On this, the fourth day after admission, rigidity gave way to flaccidity, he became oliguric, his respirations were increasingly rapid and shallow, and he died on the evening of this day. The number of abnormal mononuclear cells fell rapidly despite a rise in the total white cell count until the day of death there were $8 \%$ abnormal mononuclear cells in a total count of 26,000 . Re-examination of the cerebrospinal fluid showed no change in pressure, no increase in cells, but on the second occasion a protein content of 102.

Treatment had been with intramuscular penicillin before admission, intravenous tetracycline after admission, intravenous fluid corticotrophin, and cooling by ice.

Necropsy.-Dr. G. R. Laurenson provided the following post-mortem report :-
Respiratory System.-There was evidence of purulent bronchitis and bronchopneumonia.

Cardiovascular System.-There was some cardiac enlargement, subepicardial haemorrhage at the base of the left ventricle, and several small patches of necrosis in the wall of the left ventricle.

Liver.-The liver was grossly enlarged with mononuclear infiltration in some portal areas and prominent Kupffer cells but no significant hepatitis.

Spleen.-The spleen was enlarged, extremely congested, and showing an increased number of large mononuclear cells in the pulp.

Kidneys.-The kidneys were extremely congested with pigment casts in some tubules and degeneration of tubular epithelium but no interstitial reactions.

Lymph Nodes.-These contained numerous large mononuclear cells with pink cytoplasm.

Nervous System.-The brain, which weighed 1,770 g., was swollen and soft and the external and cut surfaces were extremely congested. The pituitary gland appeared normal. Numerous small petechiae were present beneath the dura lining the middle cranial fossa. The spinal cord also appeared congested. On sectioning the fixed brain coronally the only definite abnormality in the gross specimen apart from general congestion was a patch of haemorrhage about $5 \mathrm{~mm}$. across in the white matter of the inferior part of the right frontal lobe.

On histological examination the striking feature was the minimal degree of recognizable change. The motor cortex was oedematous and scattered pyramidal cells showed chromatolysis, some appearing as shadows only, but no inflammatory reaction was seen. In the visual cortex perivascular oedema was moderate to marked. Some of the neurones in the island of Reil showed pyknosis. In the basal ganglia there was oedema and an occasional small perivascular haemorrhage. The substantia nigra showed a small collection of microglial cells containing pigmentation. There was moderate oedema in the basis pedunculi. In the medulla there was slight oedema and a few pyknotic cells in the olivary nucleus. There was chromatolysis in some cells on the lateral cuneate nucleus and a few degenerating cells were seen in the reticular substance. The cerebellum showed oedema of the Purkinje cell layer. In the ventral horns on the thoracic spinal cord there were degenerating cells without any surrounding reaction and some similar changes in the cells of Clarke's column.

\section{Discussion}

Tidy (1952) has pointed out that where central nervous system complications occur there may be as yet no other indications of glandular fever, and indeed the neurological illness may be over before glandular fever is recognized at all. The contrary may also be found and the typical features of glandular fever run their course and subside before neurological features develop (Sucher and Schwarz, 1936; Geliebter, 1946; Silversides and Richardson, 
1950; Freedman et al., 1953; Green, 1955). It should also be noted that in other cases, even when the illness has progressed to the stage of deep coma and extensor spasms, recovery has been spontaneous (Walsh et al., 1954).

Thomsen and Vimtrup (1939) described six deaths, four of them due to respiratory paralysis, in $\mathbf{5 0 0}$ cases of glandular fever. Custer and Smith (1948) made extensive pathological observations on the basis of nine necropsies, two of which had come about from acute polyneuritis. Dolgopol and Husson (1949) reported a fatal case, designated haemorrhagic encephalomyopathy, and found 16 reported deaths of which seven were due to nervous system involvement. Silversides and Richardson (1950) listed eight from this cause. Leibowitz (1953) commented on 38 reported fatal cases, but only 28 had sufficient data to make them identifiable as glandular fever; eight had been due to involvement of the nervous system. The only other fatal neurological case that has been encountered is that of Gastaut, Radermecker, Vigouroux, and Van Bogaert (1956) but here the death of the infant described occurred a few days after a head injury and there was no confirmation of the diagnosis of glandular fever from the blood picture or heterophile antibody reactions during life.

The accounts of pathological changes in the nervous tissue based on the above necropsies have included congestion of the brain and meninges, perivascular and pericellular oedema, degenerative changes of ganglion cells in the nuclei of the midbrain and medulla, and similar changes in the Purkinje cells of the cerebellum. Perivascular haemorrhages in the spinal cord have been observed, and mononuclear infiltration of the cranial nerves, spinal roots and nerves, and in one case of the peripheral nerves. Perivascular cuffing with lymphocytes was by no means a constant feature although it was present in the airman described by Allen and Kellner (1947) who was killed while convalescent from glandular fever.

The pathogenesis of the central nervous system changes in glandular fever is of considerable interest, and one's mind immediately turns to the encephalopathies which may complicate the specific fevers. This whole subject has been reviewed by Miller, Stanton, and Gibbons (1956), who studied the neurological complications of measles, rubella, varicella, mumps, scarlet fever, and whooping cough. By comparison of pathological features they showed common changes, namely initial congestion and oedema with later perivenous infiltration and demyelination, in the encephalopathies due to specific fevers, some non-specific infections, serum sickness, drug encephalopathies and experimental encephalopathies, and they put forward a theory of allergic response to a variety of agents producing a standard pathological pattern, an "allergic neuraxitis", as they termed it. Such a theory, involving tissue reaction at any part of the nervous system, could explain the variety of clinical pictures that may occur in glandular fever as well as in the conditions they discussed.

The cerebrospinal fluid findings in glandular fever are surprisingly inconstant. Lymphocytic pleocytosis has been reported in cases with no clinical abnormalities of a neurological nature (Toomey, 1936; Schmidt and Nyfeldt, 1938; Karpinski, 1952) while cases with gross nervous system disorder have been reported with no change in the fluid at all (Crowther, 1951). The protein is likewise normal in many cases but raised in others. Although a number of earlier attempts had been made to demonstrate a positive Paul-Bunnell reaction in the cerebrospinal fluid, the first successful results were those of Silberstein, Bernstein, and Stern (1948). It is clear, therefore, that the diagnosis of glandular fever affecting the nervous system does not depend upon any typical cerebrospinal fluid picture, but rests on the clinical evidence, which may be scanty or absent, of glandular fever elsewhere, and the differential white cell picture in the blood and Paul-Bunnell reaction of the serum.

\section{Summary}

A fatal case of glandular fever with clinical features of severe encephalopathy has been presentedo and the pathological features described and pathogenesis suggested. The cerebrospinal fluid findings are much too variable to be taken as a firm guide to the nature of the encephalitic or meningitic process.

Thanks are due to Dr. J. M. Tweed who referred the case described and shared the care of the patient, and to Dr. J. D. Reid, pathologist to the Wellington Hospital, and Dr. G. R. Laurenson, formerly assistant pathologist, for the histological examinations and their interpretation.

\section{REFERENCES}

Allen, F. H., and Kellner, A. (1947). Amer. J. Path., 23, 463. Ashworth, J., and Motto, S. A. (1947). New Engl. J. Med., 237, Bernstein, T. C., and Wolff, H. G. (1950). Ann. intern. Med., 33, Bernstein, $T$.

Coogan, T. J., Martinson, D. L., and Mathews, W. H. (1945). Illinois med. J., 87, 296.

Creaturo, N. E. (1950). J. Amer. med. Ass., 143, 234.

Crowther, J. S. (1951). Brit. med. J., 2, 775 .

Custer, R. P., and Smith, E. B. (1948). Blood, 3, 830

Dolgopol, V. B., and Husson, G. S. (1949). Arch. intern. Med., 83,

Epstein, S. H., and Dameshek, W. (1931). New Engl. J. Med., 205, 1238 .

Fiese, M. J., Cheu, S., and Radding, J. (1953). A.M.A. Arch. intern. Med., 92, 438.

Fledelius, M. von (1935). Acta Ophthal. (Kbh.), 13, 150.

Freedman, M. J., Odland, L. T., and Cleve, E. A. (1953). A.M.A. Arch. Neurol. Psychiat., 69, 49. 
Garvin, J. S. (1953). J. Amer. med. Ass., 151, 293.

Gastaut, H., Radermecker, J., Vigouroux, R., and Bogaert, L. van (1956). Rev. neurol., 94, 23 .

Geliebter, S. (1946). Lancet, 2, 753.

Graha n, S. D., Schwartz, W. H., and Chapman, W. L. (1949). U.S nav. med. Bull., 49, 914.

Green. I. (1955). Neurology, 5, 366

Gsell, O. (1937). Disch. med. Wschr., 63, 1759.

Halcrow, J. P. A., Owen, L. M., and Rodger. N. O. (1943). Brit. med. J., 1,663 .

Hiller, R. I., and Fox, M. J. (1943). Marquette med. Rev., 7, 152.

Hubler, W. L., Bailey, A. A. Campbell, D. C., and Mathieson, D. R. (1951). Proc. Mayo Clin., 26, 313.

Johansen, A. H. (1931). Acta med. scand. 76, 269

Karpinski, F. E. (1952). Pediatrics, 10, 265. Kissel. P., Arnould, G., and Léval, P. (1952). Sem. Hôp. Paris, 28,

Landes, R., Reich, J. P., and Perlow, S. (1941). J. Amer. med. Ass., 116,2482

Leibowitz, S. (1953). Infectious Mononucleosis. Modern Medical Monographs No. 5 . Grune and Stratton, New York.

Librach. I. M. (1952). Brit, med. J., 1, 956.

(1954). Ibid., 2, 27.

McNeel, L. (1951). Wis. med. J., 50, 159

Marchal, G., Bargeton, and Mahoudeau (1933). Sang., 7, 431

Miller, H. G., Stanton, J. B., and Gibbons, J. L. (1956). Quart. J. Med., 25, 427.

Peters, C. H., Widerman, A., Blumberg. A., and Ricker, W. A. (1947) Arch. intern. Med., 80, 366.
Pial, J. J., Thelander, H. E., and Shaw, E. B. (1950). J. Pediat., 37, 66

Raymond, R. W., and Williams, R. L. (1948). New Engl. J. Med. 239, 542 .

Richardson, J. S. (1942). Lancet, 1, 618.

Ricker, W., Blumberg, A., Peters, C. H., and Widerman, A. (1947) Blood, 2, 217.

Rugg-Gunn, M. A. (1954). Proc. roy. Soc. Med., 47, 759.

Saksena, H. C. (1943). Brit. med. J., 2, 267.

Schmidt, V.. and Nyfeldt, A. (1938). Acta oto-laryng. (Stockh.), 26, 680 .

Schneider, T., and Michelson, D. A. (1947). S. Afr. med. J., 21, 57.

Seltzer, B. (1953), Brit, med. J., 2, 83

Silberstein, J. K., Bernstein, T. C., and Stern, T. (1948). J. Lab clin. Med., 33, 1204.

Silversides, J. L., and Richardson, J. C. (1950). Canad. med. Ass. J., 63,138

Slade, J. de R. (1946). New Engl. J. Med., 234, 753

Sucher, A., and Schwarz, E. (1936). Wien. klin. Wschr., 49, 1417.

Thomsen, S., and Vimtru J, B. (1939). Nord. Med.. 4, 3295

Tidy, Sir Henry (1946). Lancet, 2, 819.

(1952). Brit. med. J., 2, 436.

Toomey, J. A. (1936). J. Pediat., 8, 148

Vaughan, S. L., Regan, J. S., and Terplan, K. (1946). Blood, 1, 334. Walsh, 536. C., Poser, C. M., and Carter, S. (1954). Pediatrics, 13,

Zohman, B. L., and Silverman, E. G. (1942). Ann. intern. Med., 16, 1233. 